\title{
Relation between craniocerebral injury and subsequent myocardial fibrosis and heart failure Report of 3 cases
}

\author{
Jovan Rajs \\ From the Government Institute of Forensic Medicine, Stockholm, Sweden
}

The findings at necropsy in three cases of severe craniocerebral injury associated with unconsciousness are reported with special reference to the histopathological findings in the myocardium.

In the first case, death occurred 3 days after the trauma, in the second case 21 days after, and in the third case, 7 years after. Necropsy showed myocardial lesions of recent origin in the first case, stromal condensation in the myocardium in the second, and cardiac hypertrophy with coexisting patchy fibrosis of the myocardium in the third. The relation between craniocerebral injury and subsequent myocardial fibrosis is discussed.

Myocardial lesions of recent origin are found fairly often at necropsy in patients who died from certain types of intracranial disease or craniocerebral injury. These lesions have included eosinophilic degeneration and focal necrosis of the myocardium (Shkhvatsabaya, 1961), focal myocardial oedema, necrosis of myofibrils, and interstitial haemorrhage (Eichbaum and Bissetti, 1966), inflammation (Plueckhahn and Cameron, 1968), focal myocytolysis, fuchsinophilic degeneration (Connor, 1969), and myofibrillar degeneration (Reichenbach and Benditt, 1970). The main findings at necropsy were cerebral haemorrhage, cerebral abscesses, thrombosis of cerebral vessels, meningitis, ruptured aneurysm, cerebral infarction, craniocerebral injury, and primary or secondary brain tumours.

Chronic heart lesions such as myocardial fibrosis and cardiac hypertrophy may develop from recent myocardial lesions of encephalogenic origin. However, little attention has hitherto been given to this possibility.

The findings in the 3 cases reported below further substantiate the relation between craniocerebral injury and myocardial fibrosis.

\section{Patients and methods}

The records of patients with craniocerebral injury on whom necropsy was performed at this institute were reviewed with special reference to the past history and age

Received 1 September 1975. at the time of death. The available information about the past history, especially about previous cardiac disease or conditions that might have harmed the heart, is generally more detailed and reliable in cases of young adults than in those of older patients. The ages of the 3 patients presented were 25,15 , and 15 years, respectively, at the time of death. Their histories were therefore studied in more detail and were considered to be sufficiently interesting, particularly in relation to the problems discussed in this paper.

Blocks of brain, lung, liver, kidney, anterior wall of the right ventricle, septum, anterior and posterior wall of the left ventricle and papillary muscles were fixed in 4 per cent neutral formaldehyde solution for from 24 to 36 hours and thereafter embedded in paraffin. Sections $5 \mu \mathrm{m}$ thick were cut from all tissues and stained with haematoxylin-eosin and van Gieson. Sections from the myocardium were in addition stained with PAS and Mallory's PTAH, and in one case (Case 3) also with Weigert's resorcin fuchsin elastic stain, Best's carmine, Congo red, and Clarck's scharlach $\mathbf{R}$ stain (Armed Forces, Institute of Pathology, 1960).

The Table shows the principal microscopical findings in the heart, together with the length of the interval between craniocerebral injury and death of the patients.

Mononuclear and polynuclear leucocytic infiltration of the myocardium, myocytolysis, and myocardial fibrosis, respectively, were graded as follows:

Mononuclear and polynuclear leucocytic infiltration $+=$ presence of solitary cells around vessels or between muscle fibres;

$++=$ presence of clusters of leucocytes around vessels or between muscle fibres;

$+++=$ more or less diffuse infiltration of the entire myocardium. 
TABLE Histopathological findings in heart in three cases of craniocerebral injury

\begin{tabular}{|c|c|c|c|c|c|c|}
\hline \multirow{2}{*}{$\begin{array}{l}\text { Case } \\
\text { No. }\end{array}$} & \multirow{2}{*}{$\begin{array}{l}\text { Interval between } \\
\text { injury and death }\end{array}$} & \multirow[t]{2}{*}{ Macroscopical findings } & \multicolumn{4}{|c|}{ Microscopical findings } \\
\hline & & & Myocytolysis & $\begin{array}{l}\text { Mononuclear cell } \\
\text { infiltration }\end{array}$ & $\begin{array}{l}\text { Polymorphonuclear } \\
\text { leucocyte infiltration }\end{array}$ & $\begin{array}{l}\text { Myocardial } \\
\text { fibrosis }\end{array}$ \\
\hline $\begin{array}{l}1 \\
2 \\
3\end{array}$ & $\begin{array}{l}3 \text { days } \\
21 \text { days } \\
7 \text { years }\end{array}$ & $\begin{array}{l}\text { Subendocardial haemorrhage } \\
\text { Subendocardial haemorrhage } \\
\text { Cardiac hypertrophy and fibrosis }\end{array}$ & $\begin{array}{l}++t \\
++ \\
+\end{array}$ & $\begin{array}{l}+t+ \\
+t \\
+\end{array}$ & $\begin{array}{l} \pm \\
\pm \\
=\end{array}$ & $\begin{array}{l}+ \\
+t+\end{array}$ \\
\hline
\end{tabular}

For explanation of symbols see Patients and methods, pp. 396 and 397.

Myocytolysis

$+=$ presence of solitary cells showing myocytolysis;

$++=$ presence of foci of several cells showing myocytolysis;

$+++=$ a large number of foci of cells showing myocytolysis.

Myocardial fibrosis

$+=$ presence of loose granulation tissue in interstitial spaces, around vessels, or foci of such tissue-that is, evidence of stromal condensation;

$+t=$ presence of small foci of dense collagenous tissue;

$+++=$ numerous foci of collagenous tissue scattered throughout the myocardium which were even visible macroscopically.

\section{Case reports}

\section{Case 1}

The patient, a woman aged 25 years, was thrown off a horse and struck her head. A few minutes after her fall she fainted and was immediately taken to hospital. On admission she was unconscious, her pupils were fixed, but focal neurological signs were absent. A few hours after her admission the blood pressure rose from 130 $\mathrm{mmHg}(17.3 \mathrm{kPa})$ systolic and $90 \mathrm{mmHg}(12.0 \mathrm{kPa})$ diastolic to $260 \mathrm{mmHg}(34.6 \mathrm{kPa})$ systolic and 130 $\mathrm{mmHg}(17.3 \mathrm{kPa})$ diastolic. She was given dexamethasone and mannitol and this resulted in a fall of the blood pressure to $90 \mathrm{mmHg}(12.0 \mathrm{kPa})$ systolic and $60 \mathrm{mmHg}(8.0 \mathrm{kPa})$ diastolic. Leads I and III of the electrocardiogram showed sinus rhythm and ventricular extrasystoles.

The patient was deeply unconscious, with no reflexes, and despite three days on the respirator, she died. Necropsy disclosed a haematoma in the occipital region, copious subdural haemorrhage, cerebral oedema, and signs of compression of the brain-stem. The heart weighed $300 \mathrm{~g}$. There was evidence of slight subendocardial haemorrhage beneath the left aortic valve.

Microscopical examination of the myocardium showed interstitial oedema, focal necrosis of myofibrils, minute haemorrhages and round cell infiltration perivascularly and diffusely in the interstices. The changes were widespread, being most pronounced beneath the endocardium and within the papillary muscles. There was infiltration with inflammatory cells, the majority being mononuclear cells, granulocytes being scarce. There were no vascular changes or signs of fibrosis (Fig. 1 and 2). The other findings were normal. Death was attributed to compression of the brain resulting from tearing of the communicating veins of the subdural space (Brückenvenen) caused by the injury to the skull.

\section{Case 2}

The patient, a girl aged 15 years, hit her head when falling down a flight of stairs. Immediately after her fall she was dazed. A few hours later she became deeply unconscious and was taken to hospital. As there were no focal neurological symptoms her condition was attributed to some form of intoxication. A few hours after admission her blood pressure rose, the pupils were unequal, and Babinski's sign was positive on the right side. The electrocardiogram showed no abnormality. While being transferred to the neurosurgical department her respiration ceased. She was intubated. After 21 days' treatment on the respiy ator she died.

Necropsy disclosed fracture of the skull in the right parieto-occipital region and epidural haematoma: the brain tissue was soft and discoloured. The heart weighed $190 \mathrm{~g}$. There were macroscopical subendocardial haemorrhages within the upper part of the septum below the aortic valve. Microscopical examination of the myocardium showed focal oedema, necrosis of solitary myofibrils, minute haemorrhages, diffusely and perivascularly stromal condensation, inflammatory cells, which were predominantly mononuclear in type, fibroblasts, fibrocytes, solitary macrophages, and granulocytes (Fig. 3); the other findings were normal. Death was attributed to compression of the brain as a result of fracture of the skull and epidural haematoma.

\section{Case 3}

The patient, a boy aged 8 years, collided with a motor-car when cycling. On admission to a neurosurgical unit he was unconscious. He had several convulsive fits and episodes of opisthotonus. Radiography of the skull showed a fracture of the fronto-occipital region with no depression of bone fragments. Angiography of the carotid artery showed an expansive process above the tentorium of the left side.

The patient was placed on the respirator and was given dexamethasone and mannitol. After a few days he regained consciousness and was removed from the respirator. The only available information about the condition of the cardiovascular system dated from the 13th day after his accident. On that occasion the heart 


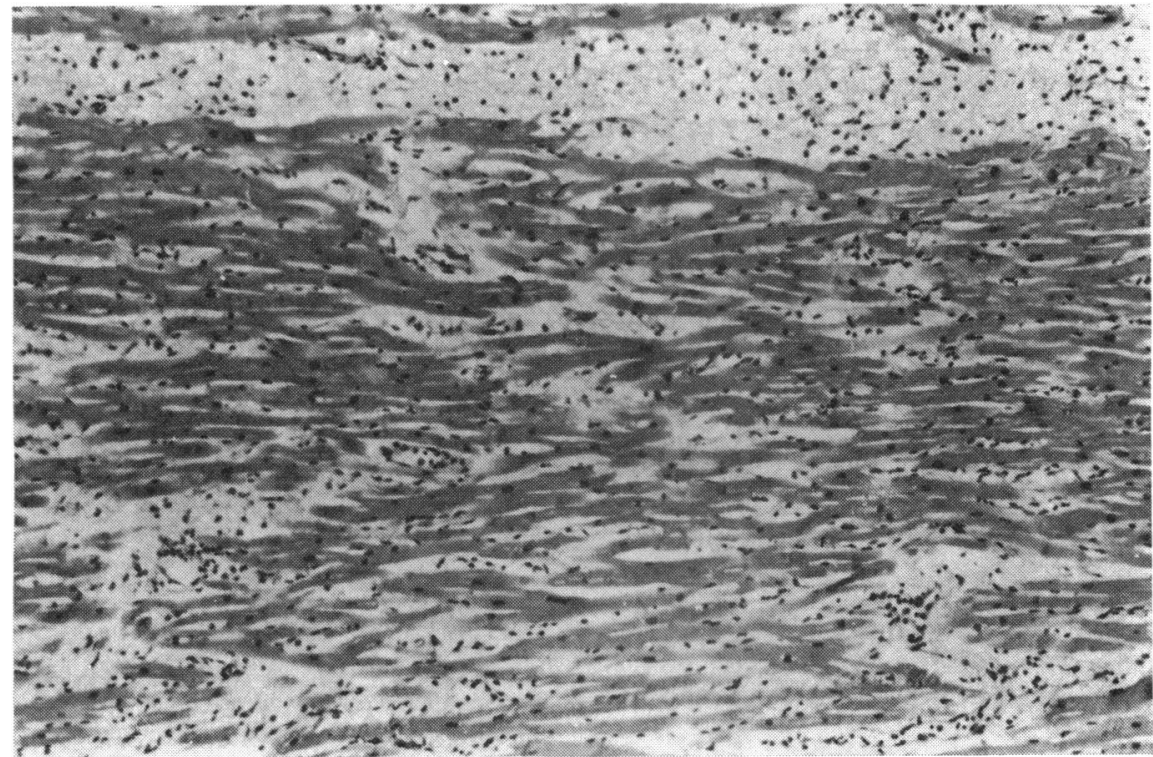

FIG. 1 Case 1. Photomicrograph showing extensive infiltration with inflammatory cells, predominantly mononuclear in type, and wide separation of myocardial fibres indicating interstitial oedema. (Haematoxylin-eosin. $\times$ 80.)

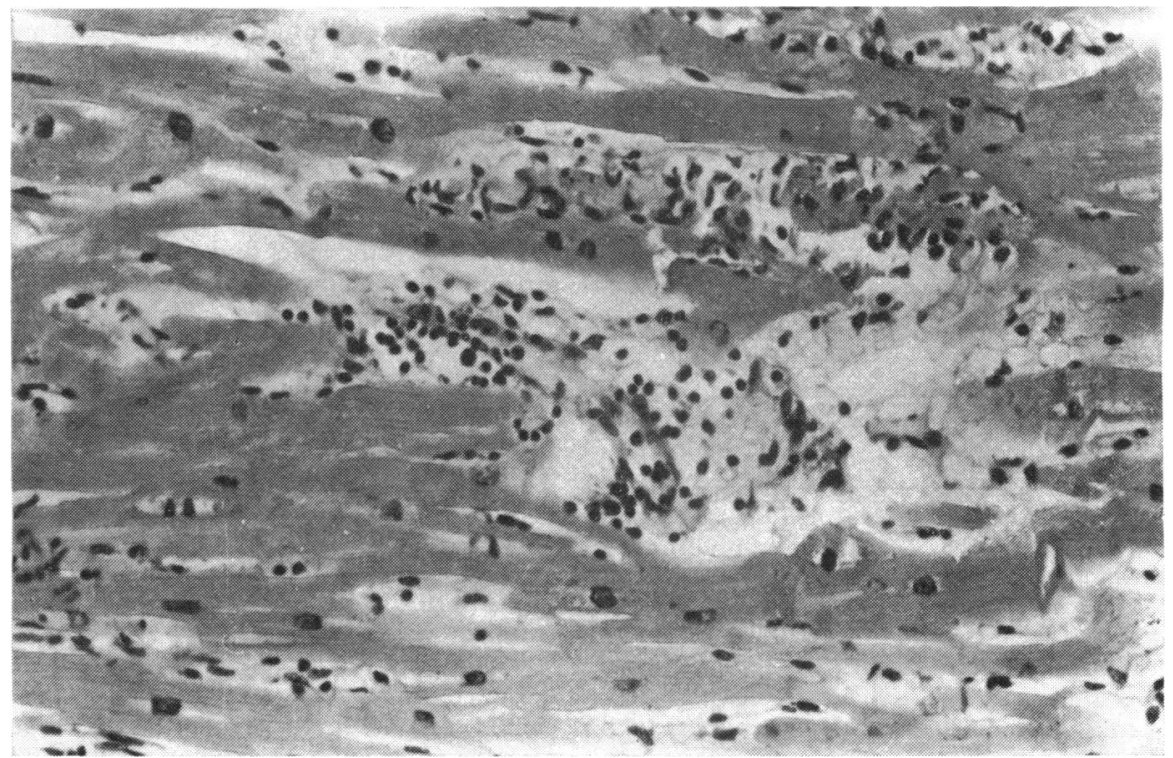

FIG. 2 Case 1. Photomicrograph showing focal necrosis of myofibrils. (Haematoxylin-eosin. $\times$ 200.) 


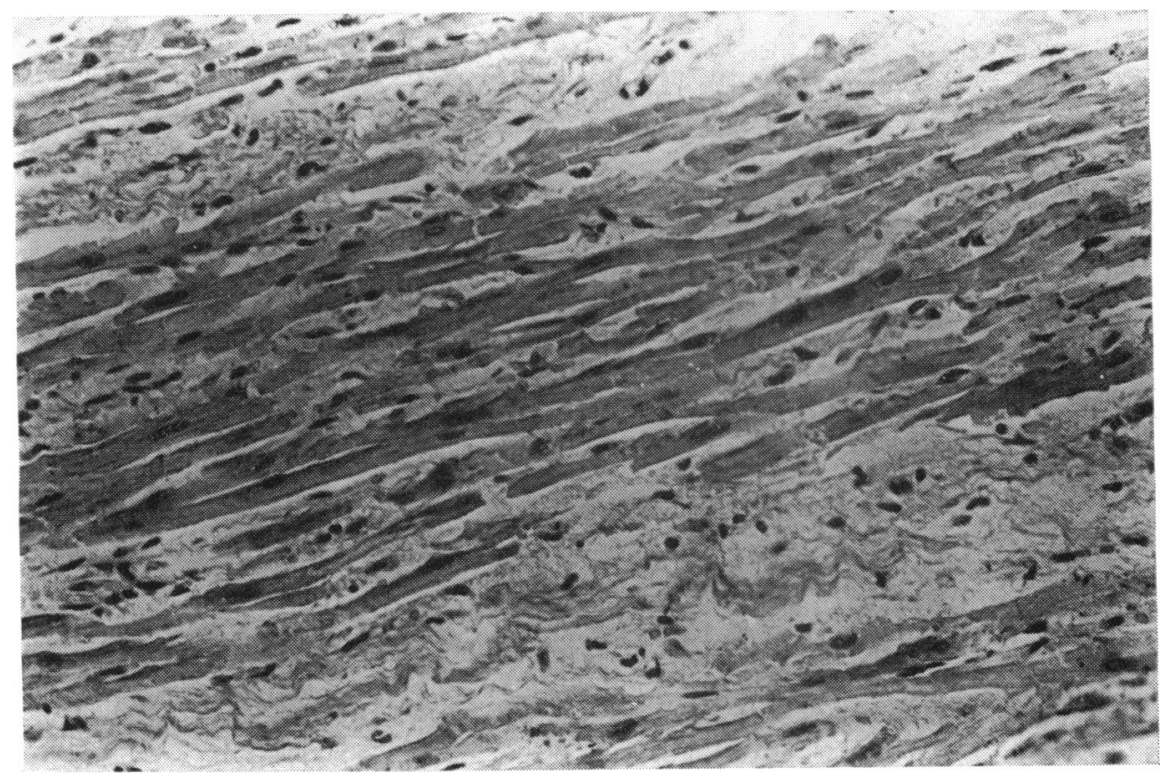

FIG. 3 Case 2. Photomicrograph showing stromal condensation in myocardium in form of proliferation of fibroblasts and deposition of collagenous fibres 21 days after trauma. (Haematoxylin-eosin. $\times$ 200.)

rhythm was regular, the heart sounds were clear, the pulse rate was $120 / \mathrm{min}$, and the blood pressure was $105 \mathrm{mmHg}(14.0 \mathrm{kPa})$ systolic and $75 \mathrm{mmHg}(10.0 \mathrm{kPa})$ diastolic. Electrocardiograms were not taken. After discharge he was able to attend school and engage in his normal spare-time occupations.

At the age of 9 years he had measles. He was ill for three weeks and was cared for at home. At the age of 11 years he had a mild form of scarlatina. He was followed up by the school medical officer at regular intervals for 7 years after his accident. The clinical and laboratory findings were always normal with no symptoms suggestive of epilepsy. At the age of 15 years, after a short sprint, he suddenly collapsed and died.

At necropsy large punched-out yellow areas denuded of their meningeal covering (plaques jaunes) were found in both temporal regions. There was no cerebral oedema; neither were there any bite marks on the tongue. The heart was enlarged, weighing $340 \mathrm{~g}$ (body weight was $55 \mathrm{~kg}$ ). There was pulmonary congestion; the myocardium showed patchy fibrosis; the valves, endocardium, and coronary arteries were normal. Microscopical examination of the myocardium revealed perivascular and focal fibrosis, hypertrophic and atrophic fibres, and minute areas of myocytolysis. There was infiltration with a few mononuclear inflammatory cells, mostly histiocytes (Fig. 4 and 5). No giant cells or granulomas were seen. The walls of the small arterial branches were thickened and fibrosed with slight endothelial proliferation. Staining with Best's carmine and Congo-red for evaluation of glycogen and amyloid was negative; there was no accumulation of lipids in the sarcoplasm.
Microscopical examination of lungs, liver, spleen, and kidneys was normal.

The immediate cause of death was considered to be acute cardiac insufficiency resulting from fibrosis of the myocardium.

\section{Discussion}

To elucidate whether the craniocerebral injury alone was the cause of death in these three cases and whether the myocardial lesions found at necropsy were sequelae of the injury or resulted from natural disease requires careful analysis of the circumstances of the injury as well as of the clinical features. Naturally, the longer the interval between the injury and death the greater the difficulties. Nevertheless it may be of crucial medicolegal importance to know the answer to these questions.

The aetiology of a diffuse myocardial fibrosis found at necropsy is difficult to determine. The myocardium reacts to various harmful effects in much the same way. According to Simpson (1967), primary myocardial lesions such as those caused by hypertension, coronary insufficiency, and viral, bacterial, spirochetal, fungal, protozoal, or trypanosomal infection may cause fibrosis. Simpson thought that diffuse fibrosis represented the end stage of different primary myocardial lesions. The damage to the heart may be so extensive that one wonders how it managed to function (Burch, Tsui, and 


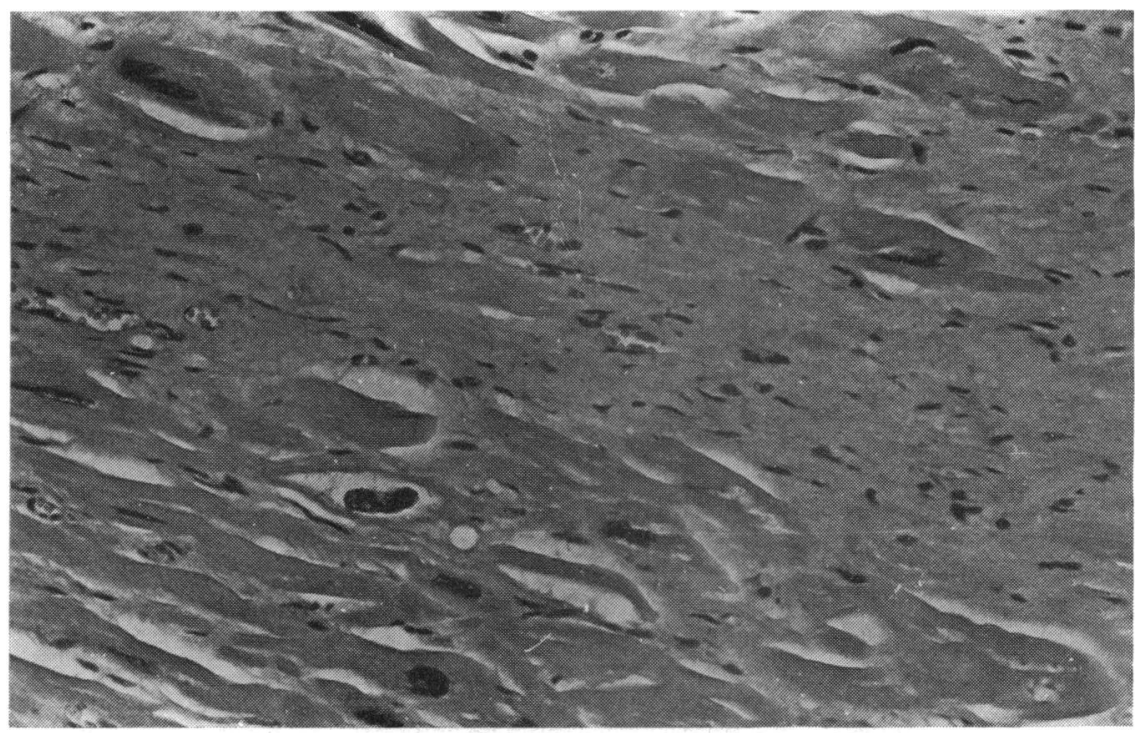

FIG. 4 Case 3. Photomicrograph showing left ventricular wall. Area of dense collagenous connective tissue separates muscle fibres, which lie singly or in small groups. Enlarged hyperchromatic nuclei indicate myocardial hypertrophy. (Haematoxylin-eosin. $\times 100$.)

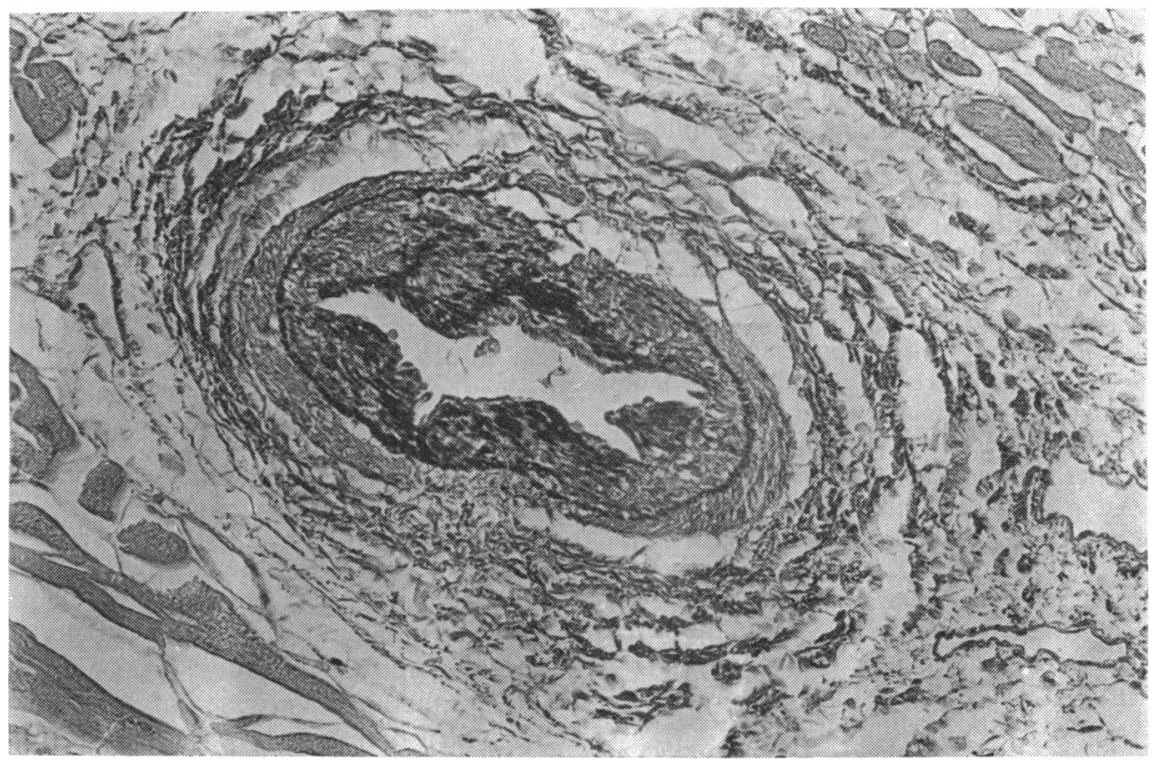

FIG. 5 Case 3. Photomicrograph showing thickening of arterial wall and increase in perivascular connective tissue. (Weigert's resorcin fuchsin elastic stain. $\times 100$. 
Harb, 1972). Myocardial lesions are known to develop secondary to craniocerebral injury. Aschenbrenner and Bodechtel (1938) reported electrocardiographic abnormalities in young patients with brain tumours. Other reports followed of abnormalities in the electrocardiogram associated with intracranial processes and craniocerebral injury in man and with similar electrocardiographic changes experimentally induced in animals (Burch, Meyers, and Abildskov, 1954; Burch, DePasquale, and Malaret, 1960; Shkhvatsabaya, 1961; Eichbaum and Bissetti, 1966; Plueckhahn and Cameron, 1968; Burch et al., 1969; Reichenbach and Benditt, 1970; Anderson, Woodburn, and Fisch, 1973; Cruickshank, Neil-Dwyer, and Stott, 1974).

Plueckhahn and Cameron (1968) differentiated a type of myocarditis that was a direct or indirect complication of trauma and which resulted from systemic hypoxia. They termed it 'traumatic myocarditis', and they reported it in 3 cases of craniocerebral injury associated with unconsciousness. Eichbaum and Bissetti (1966) assumed the pathogenesis of encephalogenic lesions of the heart to be as follows. All forms of surgical and traumatic stress stimulate sympathetic centres in the hypothalamus. This stimulation is particularly strong if the intracranial pressure increases, especially if the increase is sudden. Catecholamines are released and the resulting increased cathecholamine concentrations cause myocardial lesions and cardiovascular disturbances.

Catecholamines such as noradrenaline or isoprenaline given to experimental animals induce similar myocardial lesions (Eichbaum and Bissetti, 1966). Garbarsch et al. (1969) noted degenerative and necrotic changes in the arterial wall of rabbits after systemic oxygen deprivation for two weeks. In the processes of repair fibrosis and sclerosis similar to human arteriosclerosis develop. According to these workers similar changes in the arterial wall can be induced by the administration of exogenous catecholamines.

There are few reports on prognosis in cases of recent encephalogenic myocardial lesions. Plueckhahn and Cameron (1968) believed that infiltration with round cells or leucocytes may occur at later stages, and pointed out that this type of myocardial lesion might produce only transient clinical symptoms. Shkhvatsabaya (1961) and Shkhvatsabaya and Postnov (1967) induced changes in the electrocardiogram and myocardial necrosis and formation of granulation tissue in rabbits with cerebral stimulation by blowing air into the lateral ventricles of the brain.

According to Connor (1970) fuchsinophilic de- generation and focal myocytolysis in advanced stages are usually irreversible but they may occasionally 'heal', provided that the lesions are not too extensive and fibrosis develops. Reichenbach and Benditt (1970) believed that catecholamines might induce acute myocardial lesions in man as well as in experimental animals, and if these lesions are sufficiently extensive they can contribute to, or be the cause of, death. Repeated episodes of subarachnoid haemorrhage may result in condensation of the stroma of the heart muscle, fibrosis, and cardiac failure. These workers emphasized that more attention should be paid to these lesions when considering the causes of human cardiac disease.

The myocardial lesions in our three cases illustrate different stages in the development of encephalogenic myocardial lesions (Table). A study of the published reports suggests that Case 1 was similar to that reported by Plueckhahn and Cameron (1968) with respect to the clinical and pathological findings. This also applied to Case 2 , though an additional pathological finding was stromal condensation which, according to Reichenbach and Benditt (1970), represents a more advanced myocardial lesion than that in Case 1. Case 3 showed myocardial fibrosis resembling what Simpson (1967) termed the end stage of a primary non-specific myocardial lesion. Vascular changes in the form of fibrosis and thickening of the wall in small arterial branches, in the absence of signs of necrosis and inflammation of the vessel wall, were also morphologically non-specific in type. They recall the reparative and sclerotic changes that Garbarsch et al. (1969) identified in rabbits after oxygen deprivation as well as the postmortem findings in children described by Pesonen (1974) in cases of hypoxaemia. Pesonen suggested that these vascular lesions occurred either simultaneously with the myocardial lesions or preceded the latter-that is, hypoxic myocardial lesions are sequelae of vascular changes.

We may reasonably assume that the severe trauma to the skull and the development of myocardial fibrosis in Case 3 were related, for the following reasons. 1) The patient had a history of severe craniocerebral injury associated with unconsciousness. 2) There was nothing to show that he might have had cardiac disease before his accident. The measles and scarlatina later might have played a part in the subsequent development of cardiac lesions. However, he was followed up after his accident at regular intervals for 7 years; he never showed any signs or symptoms of cardiac disease. 3) The myocardial fibrosis was morphologically non-specific in character. 
The lesions in small arterial branches as well as the myocardial lesions may have arisen in conjunction with craniocerebral injury and may have been involved in the development of chronic ischaemic cardiac disease (cardiomyopathy), with a gradual increase of myocardial fibrosis resulting in heart failure and death. This may occur without causing any preceding symptoms.

Reports suggest that it is not only craniocerebral injury that can trigger the process in the myocardium but also intracranial disease causing an increase in intracranial pressure.

\section{Conclusions}

Acute lesions of the myocardium after craniocerebral injury are recognized increasingly and are much discussed. These lesions may give rise to fibrosis of the myocardium, resulting in cardiac insufficiency and death. In cases in which the past history includes craniocerebral injury associated with unconsciousness, and myocardial fibrosis and cardiac insufficiency are present, a relation between the latter lesions and the previous cerebral trauma should be considered.

I am grateful to Drs. Bertil Falconer, Sten Jakobsson, and Sten Orrenius, for many fruitful discussions, to Mrs. Astrid von Lancken and Mr. Sven Strömberg for technical assistance, and to Mrs. Margarethe $\mathrm{Ch}$. Pollak who revised the English.

\section{References}

Anderson, G. J., Woodburn, R., and Fisch, C. (1973). Cerebrovascular accident with unusual electrocardiographic changes. American Heart fournal, 86, 395.

Armed Forces, Institute of Pathology (1960). Manual of Histological and Special Staining Technique, 2nd ed. McGraw-Hill, New York.

Aschenbrenner, R., and Bodechtel, G. (1938). Über EKGVeränderngen bei Hirntumorkranken. Klinische Wochenschrift, 17, 298.

Burch, G. E., DePasquale, N., and Malaret, G. (1960). Selected problems in electrocardiography. Annals of Internal Medicine, 52, 587.
Burch, G. E., Meyers, R., and Abildskov, J. A. (1954). A new electrocardiographic pattern observed in cerebrovascular accidents. Circulation, 9, 719.

Burch, G. E., Sohal, R. S., Sun, S. C., and Colcolough, H. L. (1969). Effects of experimental intracranial hemorrhage on the ultrastructure of the myocardium of mice. American Heart fournal, 77, 427.

Burch, G. E., Tsui, C. Y., and Harb, J. M. (1972). Ischemic cardiomyopathy. American Heart fournal, 83, 340.

Connor, R. C. R. (1968). Heart damage associated with intracranial lesions. British Medical fournal, 3, 29.

Connor, R. C. R. (1969). Focal myocytolysis and fuchsinophilic degeneration of the myocardium of patients dying with various brain lesions. Annals of the New York Academy of Sciences, 156, 261.

Connor, R. C. R. (1970). Fuchsinophilic degeneration of myocardium in patients with intracranial lesions. British Heart fournal, 32, 81.

Cruickshank, J. M., Neil-Dwyer, G., and Stott, A. W. (1974). Possible role of catecholamines, corticosteroids and potassium in production of electrocardiographic abnormalities associated with subarachnoid haemorrhage. British Heart fournal, 36, 697.

Eichbaum, F. W., and Bissetti, P. C. (1966). Cardiovascular disturbances following acute increase of intracranial pressure. In Proceedings of the Fifth International Conference on Neuropathology, Amsterdam : Excerpta Medica Foundation, pp. 1016-1020. Ed. by F. Lüthy and A. Bischoff. Amsterdam.

Garbarsch, C., Mathiessen, M. E., Helin, P., and Lorenzen, I. (1969). Arteriosclerosis and hypoxia: gross and microscopic changes in rabbit aorta induced by systemic hypoxia. Histochemical studies. Fournal of Atherosclerosis Research, 9, 283.

Pesonen, E. (1974). Myocardial damage in children and its relation to coronary artery lesions. Acta Pathologica et Microbiologica Scandinavica, Sect. A, 82, 648.

Plueckhahn, V. D., and Cameron, J. M. (1968). Traumatic 'myocarditis' or 'myocarditis' in trauma. Medical Sciences and Law, 8, 177.

Reichenbach, D. D., and Benditt, E. P. (1970). Catecholamines and cardiomyopathy. Human Pathology, 1, p. 125.

Shkhvatsabaya, I. K. (1961). An attempt at experimental reproduction of cardiac lesions through action on the nervous system. Kardiologiya, 3, 19.

Shkhvatsabaya, I. K., and Postnov, Y. V. (1967). The influence on the heart of stimulation of the cerebral lateral ventricles in the rabbit in experimental atherosclerosis. In Atherosclerosis and Thrombosis, p. 60. Ed. by A. Myasnikov. Mir Publishers, Moscow.

Simpson, C. K. (1967). The pathology of the cardiomyopathies: myocardial fibrosis. In Modern Trends in Forensic Medicine, Vol. 2, p. 295. Butterworths, London.

Requests for reprints to Dr. Jovan Rajs, Government Institute of Forensic Medicine, Fack, 17120 Solna, Sweden. 